\title{
Produção e circulação internacionais do conhecimento sociológico: uma análise do conceito de dependência acadêmica
}

\author{
International production and circulation of sociological knowledge: an \\ analysis of the concept of academic dependence
}

\author{
Edmar Machado Braga Filho ${ }^{\text {(i) }}$
}

\begin{abstract}
Resumo O presente artigo realiza uma discussão teórica acerca do conceito de dependência acadêmica, tal como abordado por recente literatura no campo da sociologia. Partindo da contextualização do tema, são analisadas três visões distintas do fenômeno: 1) como herança colonial; 2) como modelo analítico de centro-periferia; e 3) como heterogeneidade estrutural de campos periféricos. Em seguida, é elaborada uma chave de análise que privilegia a interlocução entre campos nacionais, de um lado, e o espaço internacional da sociologia, de outro. Defende-se um modelo de dependência acadêmica relacional, que leve em conta as dinâmicas próprias dessa interdependência. Palavras-chaves Dependência acadêmica. Internacionalização. Globalização. Sociologia do conhecimento. Campo sociológico.
\end{abstract}

\begin{abstract}
This article undertakes a theoretical discussion on the concept of academic dependence, as debated by recent literature in the field of sociology. Starting from a thematic contextualization, three different perspectives of the phenomenon are analyzed: 1) as a colonial heritage; 2) as an analytical model of center-periphery; and 3) as structural heterogeneity of peripheral fields. Then, a model of analysis is elaborated, focusing on the dialogue between national fields, on the one hand, and on the international field of sociology, on the other. This article argues for relational academic dependence model, which takes into account the dynamics imposed by this interdependence.
\end{abstract}

Keywords Academic dependence. Internationalization. Globalization. Sociology of knowledge. Sociological field.

\section{INTRODUÇÃO}

As primeiras décadas do século XXI têm testemunhado a atualização de um debate sobre a produção e a circulação internacionais do conhecimento das ciências sociais. De fato, não é nova a preocupação quanto ao status da ciência produzida

a Mestre pelo Programa de Pós-Graduação em Sociologia e Antropologia pela Universidade Federal do Rio de Janeiro (PPGSA-UFRJ). 
fora dos centros capitalistas (cf. BASALLA, 1967). No âmbito das ciências humanas e sociais, essa reflexão data pelo menos desde as lutas por independência na América Latina, com pensadores críticos à subordinação do pensamento latino-americano pelas metrópoles (BEIGEL, 2016). Além disso, considerando o processo de descolonização ao longo do século XX, sobretudo daquelas regiões antes sob o domínio do Reino Unido e da França, observamos uma rica produção intelectual reunida sob o emblema do pós-colonialismo. A atualização dessa temática, sob o ponto de vista das ciências sociais, pode ser compreendida em sua interlocução com dois aspectos inter-relacionados: com as transformações decorrentes da globalização, de um lado, e com as tentativas de se fazer uma "sociologia das ciências sociais", de outro.

Verdadeira buzzword na virada do século XX para o XXI, o termo globalização entrou para o vocabulário das ciências sociais como um fenômeno que exigiria a sua reformulação metodológica e teórica, dado que os processos sociais não mais estariam confinados aos limites do Estado-nação (IANnI, 1994). Com efeito, a própria produção do conhecimento das ciências sociais vem passando por transformações desde o final da Segunda Guerra Mundial, em decorrência da emergência e do papel desempenhado por estruturas globalizantes. Entre estas, destacam-se a ampliação e integração da comunicação e da mobilidade transnacionais, a emergência de organizações e associações internacionais e regionais, a dependência de estruturas locais em relação àquelas globais, e a distribuição desigual de recursos materiais e simbólicos (Heilbron et al., 2018; VAnderstraeten; Eykens, 2018).

Diante deste quadro, autores das ciências sociais têm procurado compreender os seus efeitos sobre a produção e circulação do conhecimento, frequentemente associados aos imperativos de internacionalização pelas agências de fomento e avaliação de desempenho. Esses efeitos são sentidos desde o cotidiano da escrita, publicação e ensino (PINHEIro et al., 2018), até sua relação com a epistemologia das ciências sociais e criatividade intelectual, através de termos como "geopolítica do conhecimento" e "dependência acadêmica" (Connell, 2007; Alatas, 2003; Beigel, 2010; KeIm, 2008; Kenway; FAHey, 2009). Pelo gesto reflexivo, essas abordagens podem ser consideradas um esforço de pensar sociologicamente o conhecimento das ciências sociais sob o ponto de vista das relações de poder presentes nos processos de internacionalização do conhecimento científico.

Neste artigo, reflito sobre o último aspecto, isto é, as tentativas de compreensão sociológica das desigualdades presentes na produção e circulação internacionais do conhecimento nas ciências sociais. Especificamente, proponho uma discussão conceitual acerca do fenômeno conhecido como "dependência acadêmica", tendo 
por base a sua problematização em recente literatura sociológica. Tenciono, com essa discussão, elaborar uma formulação relacional do conceito de dependência acadêmica, que abarque não apenas a formação de um espaço internacional das ciências sociais, mas também - e sobretudo - delinear as relações entre campos sociológicos assimetricamente posicionados nesse espaço.

Além desta introdução, o artigo é estruturado em quatro seções. Na primeira, é apresentado o contexto no qual emerge o debate sobre dependência acadêmica, especificamente na sociologia. Em seguida, discuto três concepções do conceito, tais como abordadas pela literatura, visando ao estabelecimento de seus pontos fortes e de suas fragilidades. Em terceiro lugar, argumento que a dependência acadêmica pode ser mais bem compreendida como o relacionamento entre campos nacionais e o espaço internacional das ciências sociais. Neste ponto, descrevo algumas características do que consistiria esse espaço. Por fim, concluo sugerindo frentes de pesquisa empírica.

\section{AMPLIAÇÃO, DIVERSIFICAÇÃO E (RE)PRODUÇÃO DE DESIGUALDADES}

Processo decisivo para o fomento de uma comunicação global das ciências durante a segunda metade do século XX, e das ciências sociais em particular, foi a participação crescente de membros de comunidades científicas periféricas em instâncias reconhecidas como internacionais, tais como associações acadêmicas, eventos, congressos e periódicos (Heilbron, 2013; Braga Filho, 2019). Para a sociologia, podemos destacar o papel desempenhado pela International Sociological Association (ISA) ao incentivar a criação de associações nacionais da disciplina, e a sua respectiva inclusão como membro daquela. Ainda no escopo da ISA, destacam-se a promoção de congressos internacionais e o estabelecimento de periódicos que tencionam um diálogo internacional entre praticantes da ciência, como a International Sociology e a Current Sociology (Platt, 1998; Heilbron, 2018; MARTín, 2017).

Esse processo de ampliação e diversificação concorreu com a atualização de mecanismos (re)produtores de desigualdades globais na produção e circulação do conhecimento. Como apontam algumas pesquisas (Unesco, 2010; Dubrow et al., 2015), os fluxos que orientam a circulação internacional do conhecimento e de pesquisadores, as redes de colaboração científica e a participação em associações internacionais não se tornaram mais igualitários. Por vezes, as desigualdades internacionais se intensificaram. Ao mesmo tempo, a publicação em inglês e a internacionalização, em todas as suas dimensões, não implicam necessariamente abertura e diálogo mais equitativo entre pesquisadores de distintas regiões do 
mundo (MARTin, 2018). Contrariamente, o que ocorre muitas vezes é a imposição de um modelo centrado na experiência e nas tendências das academias centrais, ocasionando a subordinação da produção e circulação internacional de pesquisadores periféricos (Alatas, 2003; KeIm, 2008; Beigel, 2013). Essa imposição resulta de sistemas nacionais de avaliação da produtividade científica que incorporam critérios de "excelência internacional", num contexto generalizado de "governança neoliberal" preocupada com a competitividade dos rankings internacionais (Connell, 2012). Além disso, essa imposição também se relaciona com a centralização do artigo científico como fim último da atividade intelectual, em detrimento de outros aspectos que envolvem o trabalho acadêmico, como a docência, a orientação e a extensão.

Diversas pesquisas têm corroborado empiricamente esse fenômeno.Por exemplo, a exigência de publicação em inglês e em periódicos reconhecidos como prestigiosos e internacionais contribui para a segmentação de carreiras de cientistas vinculados a instituições do Sul Global (BEIGEL, 2014; HANAFI, 2011; RAHBARI, 2015). Essa exigência, por outro lado, não tem sido traduzida num maior incremento de publicações internacionais, além de reforçar as redes de co-autoria com autores do Norte Global, e da exigência do uso de bibliografia alheia a sua realidade local (Mosbah-Natanson; Gingras, 2013). Nesse processo, os órgãos de avaliação de pesquisa e de fomento desempenham um papel importante, tendo como uma de suas consequências não intencionais a heteronomia das agendas de pesquisa e desenvolvimento locais (VESSURI et al., 2014), o fenecimento de periódicos locais e nacionais (ОмовоwALE, 2014) ou a sua padronização segundo os modelos de publicação do Norte (Braga Filho, 2019).

Em todos esses casos, observamos uma forma específica de relacionamento entre distintas comunidades científicas no plano internacional, no que se refere à comunicação científica, à adoção de critérios avaliativos, de consagração, acreditação e estruturação de carreiras. Esse relacionamento tem sido caracterizado pela literatura recente como sendo de dependência: o desenvolvimento (ou a estruturação) de algumas comunidades científicas (ou campos) dependeria do estabelecimento de parâmetros fundamentados em outras comunidades, notadamente aquelas pertencentes aos grandes centros. Não há, contudo, um consenso na literatura sobre as razões e a forma de reprodução dessa dependência acadêmica. No que segue, delineio três visões que, não necessariamente opostas, apontam para perspectivas distintas acerca da compreensão da relação entre comunidades científicas no plano internacional. 


\section{ABORDAGENS EM TORNO DO CONCEITO DE DEPENDÊNCIA ACADÊMICA}

\subsection{DEPENDÊNCIA ACADÊMICA COMO HERANÇA COLONIAL}

Ancorando-se em discussões mais antigas sobre dependência dos chamados países do "Terceiro Mundo", no contexto da Guerra Fria (cf. GAREAU, 1988), a primeira abordagem analisada provém do sudeste asiático. Encontrou sua primeira atualização na descrição do fenômeno concebido como "imperialismo acadêmico", promovida pelo sociólogo e intelectual público malaio Hussein Alatas (2000). O conceito seria definido, para o autor, como a dominação de um povo por outro em seu mundo de pensamento, com raízes no modo colonial de produção. As características desse imperialismo, ainda em vigência para o autor, seriam análogas àquelas observadas no imperialismo político-econômico: 1) exploração do trabalho e matéria-prima das colônias; 2) conformidade dos povos subjugados; 3) tutela dos colonizados; 4) o papel secundário dos povos dominados; 5) a existência de uma racionalização científica sobre o imperialismo; e 6) o papel inferior dos profissionais provenientes das potências que trabalham e se especializam nas colônias (AlatAs, 2000, p. 23-24). Seu filho, o também sociólogo Syed Farid Alatas, em conhecido artigo de 2003, Academic Dependency and the Global Division of Labour in the Social Sciences, retoma o debate, afirmando a ocorrência de um neocolonialismo no mundo acadêmico, mas que não operaria de forma direta, como no passado. Sua manutenção se daria indiretamente, via dependência acadêmica, operando num plano estrutural.

As atuais "potências" das ciências sociais, para Farid Alatas, seriam os Estados Unidos, o Reino Unido e a França, e essa caracterização se deve, no que diz respeito à atividade científica, a esses países produzirem grande quantidade de artigos e resultados de pesquisa; à visibilidade internacional de que goza sua produção; à capacidade de influenciar as ciências sociais de outros países; e ao reconhecimento e prestígio que possuem. Para dar sustentação a essa argumentação, o autor elabora uma definição de dependência acadêmica inspirada em uma certa leitura de uma parte da tradição da teoria da dependência latino-americana. Para ele, o fenômeno em questão define-se pela "condição segundo a qual as ciências sociais de certos países são condicionadas pelo desenvolvimento e crescimento das ciências sociais de países dos quais os primeiros são subjugados" (ALATAS, 2003, p. 603). Especificamente, essa relação de subordinação ocorre quando algumas comunidades científicas podem se desenvolver segundo alguns critérios estabelecidos autonomamente, ao passo que outras comunidades apenas o fazem como um reflexo desses critérios. Essa relação opera, segundo o autor, dentro de um continuum de centro-periferia. 
As dimensões da dependência seriam várias. Em seu artigo de 2003, Farid Alatas elenca seis delas: 1 ) dependência de ideias; 2) dos meios através dos quais essas ideias circulam; 3) das tecnologias de educação; 4) da ajuda para a pesquisa e o ensino; 5) de investimento em educação; e 6) dependência dos pesquisadores da periferia de se especializarem no centro. Mais recentemente, o autor adicionou uma outra dimensão da dependência, referente ao reconhecimento internacional (Alatas, 2014). A dependência das ideias é, em sua opinião, o que qualifica a condição geral do conhecimento nos países periféricos, em grande parte decorrente da mente intelectual cativa (captivemind): uma mente acrítica e imitativa, dominada por fontes exógenas a sua realidade (Alatas, 2010, p. 58). Essa dependência diria respeito à meta-teoria e teorias, originalmente formuladas nos centros $\mathrm{e}$ reproduzidas nas periferias.

O mecanismo específico de perpetuação da dependência acadêmica se daria pelo que o autor denomina de "divisão global do trabalho" nas ciências sociais, cuja gênese data do período colonial. Essa divisão do trabalho comportaria três dimensões: divisão entre quem realiza trabalho teórico e trabalho empírico; entre pesquisas que se concentram no estudo de outros países e aquelas que se concentram em seu próprio; e, por fim, a divisão entre estudos comparativos e estudos de caso (Alatas, 2003, p. 608). Tendencialmente, os países centrais empreenderiam o trabalho dos primeiros polos, ao passo que às periferias caberiam o dos segundos.

A grande contribuição de Farid Alatas foi, a meu ver, atualizar o debate a respeito do relacionamento desigual entre comunidades científicas, sobretudo num contexto em que a demanda por internacionalização da produção científica se intensifica mundialmente, e assinalar a necessidade de mais estudos sobre o fenômeno - este último aspecto, inclusive, constituiria uma das frentes de reversão do problema. Além disso, sua ênfase na divisão global do trabalho como mecanismo reprodutor da dependência aponta, ainda que não explicitamente, para um elemento prático da reprodução do fenômeno, ainda que pouco explorado por ele. Por fim, sua concepção de dependência acadêmica está atrelada à necessidade de se pensar em critérios locais de relevância científica, enfatizando a importância de valorizar tradições locais e o uso crítico de teorias formuladas em outros contextos, portanto conformadas por outras experiências sociais (cf. Alatas F., 2001; 2010).

\section{2. "CENTRO-PERIFERIA" COMO MODEO ANALÍTICO}

$O$ relacionamento entre comunidades científicas no plano internacional foi caracterizado, no modelo anterior, segundo uma diferenciação estrutural entre centro e periferia, com destaque para os efeitos persistentes da colonização sobre 
as práticas científicas contemporâneas. Pode-se dizer que essa diferenciação é, em certa medida, mais descritiva do que analítica, visto que está subordinada a um outro elemento heurístico, este sim, vetor causal das relações entre comunidades científicas: a colonização e seus efeitos deletérios geradores da dependência acadêmica.

A socióloga Wiebke Keim (2008), pensando nisso, procura ampliar a compreensão das ciências sociais, especificamente da sociologia, no plano internacional. A primeira inovação da autora, inspirada no livro clássico de Fernando Henrique Cardoso e Enzo Faletto, Dependência e desenvolvimento na América Latina, é reconhecer o condicionamento recíproco entre centros e periferias (KеIм, 2008, p. 24), o que já evidencia um avanço em relação à perspectiva de Farid Alatas, marcada pela unilateralidade da sua concepção de dominação. Contudo, ela é cautelosa ao transplantar mecanicamente um modelo antes formulado para compreender fenômenos de ordem política e econômica, como o desenvolvimento, para o domínio da produção e circulação do conhecimento - outro distanciamento em relação ao modelo de dependência acadêmica delineado anteriormente. Dessa forma, a autora reconhece que a ciência, em suas múltiplas dimensões, deve ser considerada com uma certa autonomia em relação a outros aspectos da vida social, não estando, pois, inteiramente subordinada a constrangimentos de outra ordem. Isso posto, Keim (2008) elabora seu modelo de centro-periferia, agora com status analítico e segmentado em três dimensões complementares, capaz de explicar as dinâmicas internacionais das ciências sociais.

A primeira dimensão diz respeito à infraestrutura material e institucional de uma comunidade sociológica: o número de ingressantes, de associações científicas, uma rede de publicações que permita a comunicação científica, financiamento e condições de realização de ensino e pesquisa. Além disso, também diz respeito à divisão do trabalho em especialidades, capaz ou não de diversificar a atividade científica. Sobre essa dimensão, a autora diz que uma comunidade científica pode ser classificada como desenvolvida ou subdesenvolvida. Uma "sociologia desenvolvida", segundo Keim (2008, p. 25), seria aquela definida "como um sistema autônomo" de produção, difusão e acúmulo de conhecimento. Uma "sociologia subdesenvolvida", em contrapartida, define-se pela ausência de grande parte dessas características, ou pela sua incapacidade de possuí-las.

A segunda dimensão é concernente à capacidade de reprodução de uma comunidade sociológica, seja no âmbito da formação de pesquisadores, de instituições e de conhecimento. Assim, uma comunidade sociológica pode ser autônoma ou dependente. Essa distinção faria sentido, para Keim, pois mesmo possuindo infra- 
estrutura material para a produção do conhecimento, uma comunidade sociológica pode depender de referenciais teóricos, metodologias, conceitos, certificação profissional e meios de difusão que lhe são exógenos. Portanto, a diferença crucial entre uma sociologia autônoma e uma dependente é que a primeira se beneficiaria dos intercâmbios internacionais, ao passo que para a segunda, eles seriam uma condição necessária para se reproduzir.

Por fim, temos a terceira dimensão, que diz respeito ao reconhecimento internacional. A autora classifica essa dimensão entre uma sociologia marginal ou central. Centralidade se referiria àquelas sociologias internacionalmente visíveis, reconhecidamente o "núcleo" (core) da disciplina. Essa posição lhes confere a capacidade de influenciar tópicos de pesquisa, temas relevantes, referenciais teóricos, metodologias apropriadas, estabelecendo escolas, tradições e paradigmas científicos. As sociologias marginais, por outro lado, não possuem reconhecimento internacional, são ignoradas pela comunidade internacional, e essa ignorância não seria considerada a princípio como um problema. A autora diz que essa é a condição geral das sociologias feitas na África e na América Latina. Dentre os indicadores empíricos de que uma comunidade é internacionalmente marginal, merecem destaque as bases de indexação mais prestigiadas, a divisão internacional do trabalho acadêmico (nos termos de Farid Alatas) e a necessidade de se tornar "exótico" ou se particularizar para ganhar interesse internacional, seja em publicações, palestras ou aulas em instituições de comunidades centrais.

Em texto mais recente (KeIM, 2014), a autora procura reelaborar alguns de seus pontos, abrangendo o escopo de seu modelo e dissipando possíveis ambiguidades. O primeiro ponto notável é o seu distanciamento da visão difusionista da produção e circulação do conhecimento, proeminente em Basalla (1967), caracterizada pela unilateralidade e pelo protagonismo do Ocidente. Segundo o difusionismo, as nações outrora colonizadas teriam importado passivamente o conhecimento produzido exclusivamente pelas metrópoles - uma visão muito próxima, por exemplo, daquela proposta por Farid Alatas. Esse movimento da autora aponta para uma tentativa de teorização que leve em conta a agência de atores das "sociologias periféricas" no processo de circulação do conhecimento para além de uma "importação" mecânica.

Outro avanço foi apontar para outras unidades de análises que não aquelas centradas nos estados nacionais. Em seu artigo de 2008, fazia referência apenas a esses espaços de produção do conhecimento quando diz, por exemplo, "sociologia japonesa" ou "sociologia palestina". Em sua atualização, seu comprometimento com a ideia de circulação exige a valorização de outras escalas, como campos regionais 
e redes transnacionais. Aliás, uma de suas principais mudanças foi incorporar a própria noção de campo para compreender a forma como o conhecimento circula. Ela o faz partindo de uma crítica do texto clássico de Pierre Bourdieu sobre circulação de ideias (cf. BourdiEu, 1999), argumentando contra a sua ênfase na unidade de análise nacional e discordando da perspectiva do sociólogo francês, segundo a qual a circulação ocorre entre agentes que compartilham posição estrutural análoga entre os campos. Segundo ela, a posição de Bourdieu pressuporia a existência de um campo nacional de antemão, deformador da circulação internacional das ideias. Essa postura negligenciaria o fato de que a própria circulação pode contribuir para a estruturação de "campos dependentes".

Sem dúvida, sua reformulação do modelo inicialmente proposto de centro e periferia, mais analítico que descritivo, para a compreensão da circulação internacional das ideias constitui um importante avanço. Isso é notório quando a autora diz que toda análise da circulação do conhecimento, seja através de textos, ideias, ou incorporados em pesquisadores, deve necessariamente levar em conta as hierarquias e desigualdades (materiais e simbólicas) que operam dentro da comunidade internacional, afetando de forma diferencial a integração e a participação de campos científicos.

\subsection{A HETEROGENEIDADE ESTRUTURAL DOS CAMPOS PERIFÉRICOS}

A terceira e última visão sobre dependência acadêmica aqui abordada é, em muitos aspectos, crítica em relação aos outros dois modelos. As formulações da socióloga argentina Fernanda Beigel (2010, 2013, 2016), diferentemente das de Wiebke Keim e Farid Alatas, não partem de conceitos mais abstratos, como aqueles de divisão internacional do trabalho, imperialismo acadêmico e centro e periferia, para então compreender o relacionamento entre comunidades científicas diferencialmente posicionadas no âmbito internacional. Seus estudos se fundamentam em situações histórico-concretas, logo específicas, para daí tirar conclusões mais gerais a respeito do fenômeno em causa. Nesse sentido, seu programa de pesquisa segue uma lógica mais indutiva que dedutiva, tendo como universo empírico os processos de profissionalização e autonomização dos campos acadêmicos da América Latina, seu principal universo de análise.

Outra inovação proposta por Beigel é o seu uso particular de campo social. Se a incorporação crítica mais tardia da Keim acerca da noção de campo questiona a suposta ênfase de Bourdieu na unidade nacional, bem como sugere os efeitos da circulação sobre a estruturação de campos periféricos, para Beigel, o que está em jogo é justamente a noção de "autonomia", com o "nacional" constituindo 
importante unidade de análise na compreensão das dinâmicas científicas de regiões periféricas (BEIGEL, 2010, p. 17). Tomado não como um fim em si mesmo ou como um reflexo do que deveria ser um campo autônomo (sempre inspirado em modelos de "outras latitudes"), ela analisa o complexo processo de autonomização do campo acadêmico em regiões como a América Latina. A noção de "elasticidade" da autonomia é central em sua análise, dada sua ênfase sobre as dinâmicas históricas que se relacionam com a estruturação dos campos periféricos. Dessa forma, temos a expansão da autonomia universitária e a criação de um circuito regional de consagração acadêmica, como foi o caso na América Latina, com importante papel desempenhado pelo Chile em meados da década de 1960, constituindo um polo de atração de pesquisadores da região com a criação de institutos de pesquisa, como a Comissão Econômica para a América Latina e o Caribe (Cepal), a Faculdade Latino Americana de Ciências Sociais (Flacso) e o Conselho Latino Americano de Ciências Sociais (Clacso). Por outro lado, observamos a sua contração, derivada da repressão exercida pelos regimes ditatoriais sobre a produção universitária entre as décadas de 1960 e 1990.

Relevante para os fins desse artigo é a sua aproximação entre uma forma de autonomia e algumas dinâmicas internacionais. Ou seja, vinculada aos efeitos da "internacionalização" do campo científico e das distintas forças que operam na circulação internacional das ideias. Nesse âmbito, a dependência acadêmica pode ser definida operativamente, referindo-se à estrutura desigual de produção e circulação do conhecimento, historicamente construída nos chamados "centros de excelência" sem a participação das comunidades científicas periféricas. Esse processo envolveria a paulatina valorização da publicação de artigos em periódicos especializados, tomados como critérios avaliativos não apenas da "excelência" científica por parte de organismos públicos, como também por parte de institutos públicos e privados de financiamento para pesquisa e estruturação das carreiras individuais.

Esses modelos de avaliação, reconhecimento e acreditação científica se generalizaram para além dos "centros de excelência", constituindo o que a autora chama de "sistema acadêmico mundial" (SAM), conformando os circuitos de publicação, prestígio e consagração denominados de "corrente principal”. O SAM se define pela 1) "universalização" da bibliometria como ferramenta de avaliação da ciência; 2) pela supremacia do inglês nas publicações internacionais; e 3) pela concentração de capital acadêmico em determinados polos. Trata-se, portanto, de uma relação de dominação simbólica, que hierarquiza distintos circuitos de prestígio acadêmico, tanto no âmbito das publicações quanto no das mobilidades. 
Corolário dessa hierarquização é que a posição de determinado campo científico ou de um determinado investigador se relaciona com sua integração histórica aos circuitos da corrente principal. Com isso, segmenta-se não apenas a profissionalização em campos periféricos entre aqueles com maior inserção internacional, e os que possuem redes locais: hierarquiza-se também os circuitos de publicação - transnacional, nacional, regional, local e internacional - com distintos impactos sobre a estruturação das carreiras em termos de avaliação da produção científica e de progressão de carreira (Beigel, 2014).

Em suma, o novo caráter da dependência acadêmica, para Beigel, manifesta-se na crescente heterogeneidade estrutural do campo, na heteronomia dos critérios de avaliação e na externalização dos princípios de legitimação da produção científica (BEIGEL, 2014, p. 13). Ela é marcada por uma tensão entre duas culturas avaliativas, qualificadas como antípodas por Beigel, de práticas científicas em campos periféricos. De um lado, uma menos ligada a um "capitalismo acadêmico", seguindo critérios endogâmicos regionais e locais de prestígio e consagração acadêmicos, ainda que pouco articulados; de outro, a opção pela internacionalização segundo critérios estabelecidos pelos "centros de excelência", apegando-se à ilusão de ser parte das normas da "ciência universal", ao preço de uma heteronomia crescente em relação aos temas relevantes localmente.

Comparada às outras formulações, a de Beigel resulta mais frutífera para a construção de uma perspectiva relacional. Se em Wiebke Keim e Farid Alatas é possível verificar, como pressuposto de suas classificações, a associação da centralidade de um campo no cenário internacional com a produção de conhecimento original, Beigel a rejeita, pontuando para momentos de tensão entre autonomia e heteronomia dos campos periféricos e para distintas formas de produção do conhecimento. Ainda que aqueles autores observem o potencial dos campos periféricos para a produção de conhecimento original e criativo, seja através dos "discursos alternativos" (AlatAS, 2010) ou das "tendências ou correntes contra hegemônicas" (KeIm, 2011), é importante não perder de vista os distintos processos de profissionalização e configuração do campo acadêmico de cada região "periférica", para não universalizar experiências historicamente situadas. Nesse sentido, a conceitualização de Beigel é mais oportuna, por enfatizar o aspecto relacional entre, de um lado, um modelo hegemônico que tende a se universalizar ("SAM") e, de outro, processos de profissionalização e de formação de campos periféricos. Esse relacionamento é marcado pela sua dinamicidade, pois envolve distintos agentes e interesses, não recaindo, em suas palavras, numa "auto percepção alienante" das próprias tradições intelectuais locais. 


\subsection{LIMITES DAS ABORDAGENS}

Após a discussão acima das perspectivas em torno do fenômeno da dependência acadêmica, cabe pontuar o que considero problemático em suas formulações. Procedendo dessa forma, tenciono elaborar uma chave de análise para compreender o relacionamento desigual entre comunidades científicas no plano internacional, incorporando algumas de suas formulações e agregando outros aspectos ainda não explorados até aqui.

Primeiramente, a perspectiva oferecida por Farid Alatas é demasiadamente estrutural e mecânica, na medida em que não há muito espaço para a agência dos pesquisadores. Evidência disso é a importância atribuída à "mente cativa" na perpetuação de ideias e teorias do centro, problemática não apenas pela passividade concedida aos agentes sociais, mas também por creditar a um passado colonial a criação de estruturas que operariam no plano cognitivo - como isso ocorre, de fato, não está claro. Aliás, ainda que lance mão de uma corrente teórica latino-americana para dar sustentação ao seu argumento, o autor tende a pensar majoritariamente no contexto de colonização tal como ocorreu no sudeste asiático, sendo, assim, desatento ao fato de que na América Latina o processo foi distinto em vários aspectos, a começar pelos colonizadores. $\mathrm{O}$ autor também dá ênfase para regiões geográficas em sua operacionalização conceitual, homogeneizando a "comunidade científica" tanto de países centrais quanto de periféricos, deixando de lado as relações internas a essas comunidades, diferencialmente distribuídas internacionalmente. Com isso, o autor não leva em conta a existência de grupos distintos, convivendo num mesmo país, região ou mesmo numa comunidade científica, que possam vir a ter interesses específicos e, muitas vezes, conflitivos - uma das contribuições mais sofisticadas da teoria da dependência latino-americana, negligenciada pelo autor (cf. CARDOSO; FALETTO, 2004).

Já em Keim, há uma particularidade na forma como conceitua analiticamente "centro" e "periferia" que pode ser considerada pouco dinâmica, constituindo um instrumento heurístico limitado para apreender a relação entre pesquisadores no âmbito internacional. Mantida mesmo em seus trabalhos mais recentes, a sua classificação das diferentes ciências sociais produzidas internacionalmente tende a restringir alguns fenômenos e conceitos, sobretudo o de autonomia, segundo uma única chave de leitura possível. A autonomia de um campo científico não é uma qualificação absoluta, mas sempre relativa, e isso se aplica também aos campos mais bem situados no sistema acadêmico mundial. Epítome disso é o próprio campo sociológico nos Estados Unidos, que, a despeito de exercer influência mundial, pode não ser tão autônomo se levarmos em consideração as disputas de poder do campo 
cultural americano mais amplo, as imposições de critérios avaliativos de agências de fomento e os ditames da administração universitária, que tendem a priorizar pesquisas empíricas e com utilidade de maximização econômica (KRAUSE, 2016; STEINMETz, 2018). Em outras palavras, centralidade não é sinônimo de autonomia.

Essa problemática está na raiz de seu próprio gesto classificatório, já que nele está embutido uma comparação e, como tal, pressupõe a definição de parâmetros prévios de contraste ou afinidade. Nesse sentido, "as classificações práticas estão sempre subordinadas a funções práticas e orientadas para a produção de efeitos sociais" (BourdiEU, 2008, p. 107). Quando o discurso científico utiliza termos como "desenvolvido" e "subdesenvolvido", "autônomo" e "dependente" e até mesmo "central" e "periférico" para classificar diferentes "sociologias", ou seja, quando erige categorias com funções práticas à qualidade científica, contribui para a perpetuação de uma determinada visão de mundo. Não à toa, o que fica implícito em seu modelo é que o princípio classificatório entre as distintas "sociologias" internacionalmente posicionadas tem como inspiração o "modelo" hegemônico das ciências sociais, as quais seriam, em seus termos, necessariamente desenvolvidas, autônomas e centrais, pois só a partir do estabelecimento desse critério seria possível nomear as outras como subdesenvolvidas, dependentes e marginais ${ }^{1}$.

Por fim, um elemento problemático na abordagem de Beigel é a sua tendência a homogeneizar um espaço social que tem se caracterizado nos últimos anos pelo conflito e pela disputa em torno de seu significado. Refiro-me à noção de "internacional". Sua ênfase nos distintos circuitos de consagração e nas hierarquias que eles estabelecem, tendo em vista o SAM, associa necessariamente as publicações em inglês e em periódicos ditos da corrente principal à dominação sobre a produção periférica. De fato, a submissão de artigos a esses periódicos envolve muitas vezes a subordinação a critérios nacionais (por exemplo, um periódico da Associação Americana de Sociologia) que não levam em conta, ou não se interessam, pelo diálogo mais internacional, ainda que sejam considerados por agências de fomento de campos periféricos como "internacionais" (BEIGEL, 2014; MEDINA, 2014). A dominação simbólica também se expressa, evidentemente, no aprendizado e proficiência do inglês, dominante no cenário internacional.

A despeito desses aspectos, cabe questionar em que medida as publicações nos circuitos da corrente principal necessariamente implicam a alienação e o arrefecimento de temas locais, tendo em vista o reconhecimento crescente de

1 Em seu artigo de 2003, Farid Alatas incorre na mesma estratégia, ao classificar as ciências sociais como centrais, periféricas e semiperiféricas. Ao fazê-lo, julga a produção das ciências sociais periféricas tendo em vista o modelo daquelas centrais. 
instituições, editores e autores em relação às desigualdades presentes na circulação internacional do conhecimento e nas especificidades de sua produção em contextos distintos (MARTíN, 2018), sinalizando a reflexividade própria do mundo social, nos termos de Giddens (1996). Vale lembrar que, para este, o conhecimento sociológico estaria submetido a uma "hermenêutica dupla", através da qual os atores sociais interpretam tal conhecimento, tendo o potencial de reorientar suas condutas e ações, modificando, pois, o próprio mundo social. Isso exigiria do sociólogo uma reinterpretação desse mundo, sempre em mutação. O mundo social em questão seria o próprio mundo acadêmico. $O$ crescente questionamento do significado de "internacional", as críticas em relação ao eurocentrismo, ao "colonialismo acadêmico" e à própria dependência acadêmica, têm implicações para o mundo editorial, institucional e para as instâncias de ensino e pesquisa. Dessa forma, trata-se de um problema empírico saber em que condições se dá a circulação do conhecimento nessa modalidade, como também nos planos regional e nacional.

\section{CAMPOS NACIONAIS E ESPAÇO INTERNACIONAL}

Dos autores mencionados, Keim e Beigel utilizam o conceito de campo para compreender a relação entre as práticas científicas nacionais e as dinâmicas internacionais. Argumentei que a primeira oferece ferramentas úteis para pensar a interlocução entre nacional e internacional, ao reconhecer que a circulação do conhecimento é atravessada por desigualdades materiais e simbólicas, afetando, por isso, a estrutura de determinados campos. Contudo, sua preocupação classificatória deve ser vista com cautela, pelos critérios que a embasam e por obscurecer a noção de autonomia científica. Já a segunda autora evidencia a complexidade da autonomia dos campos periféricos, ao mesmo tempo em que reconhece a existência de distintos circuitos de publicação e consagração para além da corrente principal. Apesar disso, acredito ser problemático homogeneizar o espaço internacional, considerando a reflexividade do conhecimento sociológico e as disputas em torno de seu sentido.

Como as autoras, considero a noção de campo frutífera por romper tanto com a determinação total da atividade científica segundo outros fatores da vida social mais ampla, como também recusar uma visão "purista", como se não houvesse nenhuma interferência externa ao mundo da ciência. Constitui, assim, um espaço intermediário de um mundo social relativamente autônomo e dinâmico, que cria e obedece às suas próprias leis de funcionamento (Bourdieu, 1983; 2003; 2004). O seu uso confere uma densidade para a análise do fenômeno da dependência acadêmica, aprofundando abordagens que creditam a posição dominada de determinados 
saberes e comunidades científicas a fatores preponderantemente externos, como aqueles relacionados a processos históricos mais amplos de subjugação política e econômica.

Recentemente, algumas pesquisas têm estendido a noção de campo científico para unidades de análise além das fronteiras nacionais, argumentando que o que vemos hoje é a emergência de um "campo global” das ciências sociais, caracterizado por uma estrutura desigual, com um ou dois polos dominantes e uma gama de periferias e semi-periferias como polo dominado (HeILBRon, 2013), conservando semelhanças, em certa medida, ao que Fernanda Beigel denomina "sistema acadêmico mundial”. Esse campo global seria constituído por formas pretéritas de organizações internacionais, que presenciaram uma inclusão global maior de participantes, como é o caso da ISA (Dubrow et al, 2015; Oommen, 2016), mas também o surgimento de outras organizações, como periódicos internacionais, congressos e redes que aspiram a um diálogo global mais equânime (VANDERSTRAETEN; EYKEns, 2018). Ao artigo inaugural de Heilbron (2013), somaram-se outros que postulam a necessidade de se pensar em campos transnacionais e globais, dado que a noção de campo parte das relações entre agentes, e não de escalas pré-definidas (Go; KraUSE, 2016).

No caso específico da sociologia, Krause (2016) destaca a prevalência de "sistemas-modelo", que atuariam funcionalmente de forma a garantir a padronização da comunicação científica. No caso, os sistemas-modelo que operam na disciplina no âmbito internacional seriam os cânones clássicos e contemporâneos, os lugares legítimos e os temas de pesquisa que têm o "Ocidente" como horizonte. Por isso, convertem-se em capital específico no campo global, dado o acesso direto que pesquisadores de alguns campos nacionais teriam a esses sistemas-modelos. A autora quer enfatizar com isso que a disputa também se daria, internacionalmente, em torno da definição desses sistemas, com a entrada crescente de agentes posicionados em outras regiões do mundo.

Sobre a formação e autonomização dos campos globais, o esforço teórico levado a cabo por Buchholz (2016) merece destaque. A fim de não reificar processos sociais, como é comum nas teorizações tradicionais sobre globalização² a socióloga lança mão do procedimento conhecido como "teorização analítica", operando uma redução de um modelo teórico aos seus aspectos elementares. No caso, a autora

2 Esse problema foi primeiramente abordado por Connell (2007), a partir da constatação de que muitos teóricos da globalização reificam a noção de uma "sociedade global", atribuindo características das sociedades nacionais (do Norte) para uma dimensão global sem levar em conta de fato as experiências e os contextos globais. 
salienta os atributos essenciais que conformam um determinado campo, para em seguida pensá-lo globalmente. Ao fazê-lo, estabelece uma tipologia entre a "autonomia funcional" - teorizada por Bourdieu como diferenciação entre espaços sociais com distintas lógicas e práticas; e a "autonomia vertical" - que mantém as mesmas práticas e interesses, mas altera sua escala. Assim, um campo global pode emergir através da autonomização vertical de diferentes campos nacionais, que cada vez mais interagem entre si. O contrário também pode ocorrer: a partir de um campo global podem surgir campos nacionais. Uma definição de campo global envolve, dessa forma, ao menos quatro aspectos: 1) esfera de práticas especializadas; 2) escala transcontinental; 3) autonomia funcional em relação a outros campos e 4) autonomia vertical em relação a outros campos "mais baixos" em nível de organização social dentro da mesma esfera de práticas.

Os recentes esforços de teorização acerca da existência de campos globais são representativos de um movimento de interesse pela renovação da teoria dos campos na compreensão de fenômenos que escapam da escala nacional, apontando para a sua atualidade e a relevância no âmbito mais geral da teoria sociológica. Apesar disso, no que tange à consolidação de um campo global da sociologia, compartilho o ceticismo de Ortiz (2016). Para ele, não há autonomia suficiente para a delimitação de uma lógica de campo, como também não se verifica uma interação orgânica entre agentes do mundo todo - o que qualificaria o adjetivo "global”. De forma mais geral, Dezaley e Madsen (2013, p. 47) argumentam que a relação entre campos nacionais e espaços internacionais não implica de forma alguma postular a existência ou a gênese de um espaço das relações internacionais estruturado segundo uma lógica específica de campo.

Dessa forma, o âmbito "internacional" da sociologia pode ser melhor visto como um espaço social internacional. A noção de espaço social conserva as propriedades agonísticas presentes no conceito de campo sem, contudo, preocupar-se com sua autonomização, ou com o princípio segundo o qual possuiria uma lógica interna de funcionamento e uma comunicação orgânica entre os agentes que o compõem. Com efeito, essa diferenciação entre campos e espaços é mais analítica, uma vez que o próprio Bourdieu não pressupõe que essas noções sejam facilmente delimitáveis (Hey, 2008).

O espaço internacional da sociologia aqui conceitualmente delineado é composto não só por organizações que tencionam um diálogo global, mas também por agentes primariamente posicionados em campos nacionais. É um espaço hierarquizado conforme a conceituação do SAM de Beigel (2013), em que pese o idioma hegemônico (inglês), a universalização da bibliometria e do artigo como 
critérios avaliativos e de produção científica, e a distribuição desigual de recursos materiais e simbólicos em determinados polos. Essa hierarquização reforça a marginalização de determinadas produções científicas (KeIM, 2008), dificultando $\mathrm{o}$ acesso e a análise de experiências sociais no plano global.

Cabe, aqui, pensar nos mecanismos que atuam na consolidação desse espaço. Para isso, voltemos ao modelo elaborado por Bulchholz (2016) para descrever o processo de formação de campos globais, pensando, todavia, analogicamente a formação do espaço internacional da sociologia. O primeiro aspecto envolve a criação de instituições voltadas para trocas e intercâmbios internacionais. Assim, podemos pensar as associações regionais e internacionais de sociologia e os congressos e fóruns que elas realizam; os periódicos voltados para discussões internacionais; instituições de pesquisa e fomento que atuam globalmente - em suma, todas as instituições que podem ser locus de disputas entre agentes vinculados a campos nacionais. Há, dessa forma, uma infraestrutura institucional que torna regular o intercâmbio e a competição numa escala global (ou, no caso, internacional)..

O segundo mecanismo apontado pela autora diz respeito à formação de um discurso específico ao campo global, de um "olhar global" particular. Em nosso caso, isso pode ser visto nos recentes debates em torno da "sociologia global" (Burawor, 2009; BHAMBRA, 2014), que procuram não apenas estabelecer um diálogo mais equânime entre as diferentes sociologias realizadas no mundo, como também repensar os cânones disciplinares por essa perspectiva. É no bojo desse regime discursivo que podemos situar a apropriação pelas ciências sociais das críticas pós e decoloniais (Costa, 2006; KNöBl, 2015; BHAMBRA, 2014), como também da necessidade de se pensar em "antropologias mundiais" (Ribeiro, 2014). Criam-se, dessa forma, práticas acadêmicas que visam instaurar critérios de apreciação que levem em conta a relevância internacional de uma pesquisa, o escopo global de um determinado tema e etc.

Por fim, o terceiro mecanismo trata da formação institucional de avaliação, apreciação e de capitais propriamente internacionais. No espaço internacional da sociologia, essas instituições seriam aquelas que procuram ranquear as universidades segundo critérios arbitrários, que levam em conta a dimensão internacional (também arbitrária) de produção e práticas científicas. Esses critérios, que tendem a favorecer o modelo americano de fazer ciência (MARGINSON, 2008), não apenas hierarquizam instituições e produções no plano internacional, como também estratificam campos nacionais através das políticas de financiamento. 
Ainda que fortemente desigual, a incorporação crescente de agentes de campos periféricos no espaço internacional tem favorecido cada vez mais a contestação dos parâmetros hegemônicos de produção do conhecimento, e o próprio sentido de "internacional" está em disputa. Se, por um lado, os campos nacionais podem ser segmentados entre agentes com grande inserção internacional e aqueles com maior engajamento local, por outro, no espaço internacional, podemos presenciar a oposição entre os proponentes de uma internacionalização "ortodoxa" e aquela "heterodoxa" (KRAUSE, 2016, p. 197). A internacionalização ortodoxa envolveria modelos pretensamente universais de teoria social, de práticas e rotinas acadêmicas, avaliação, critérios de relevância, metodologias e temas de pesquisa legítimos. Alternativamente, no polo heterodoxo, há as críticas ao eurocentrismo das teorias sociais, a apropriação das vertentes críticas pós e decoloniais, e as chamadas "teorias do Sul Global”. Assim, aquilo que constituiria a forma legítima de internacionalização é em si um objeto de disputa entre cientistas, organizações, mas também por agentes externos ao espaço internacional, como a Organização das Nações Unidas para a Educação, a Ciência e a Cultura (UNESCO), fundações filantrópicas e, mais genericamente, agências de financiamento (BONCOURT, 2018). Dessa forma, superando tanto o objetivismo e o subjetivismo na compreensão do mundo social, o que se denomina "internacionalização" não deve ser pensado como um processo externo às dinâmicas que estruturam a produção das ciências sociais, mas, pelo contrário, como um processo estruturante e estruturado por disputas envolvendo pesquisadores e organizações diversas.

A existência e a pertinência desse polo crítico (ou heterodoxo) pressupõem as condições objetivas necessárias para a generalização de seus postulados, através da criação de ambientes propícios para a produção do conhecimento. Esse processo envolve, no âmbito propriamente nacional, a institucionalização das ciências sociais periféricas, além de políticas públicas de fomento à ciência e ao ensino superior e à criação de programas de pós-graduação. Nessas condições, a ocorrência de uma "desobediência epistemológica” não é apenas possível, como plausível (ORTIZ, 2016).

Por fim, é importante ressaltar que a inserção internacional do conhecimento sociológico também opera em outros dois planos de dominação simbólica. Primeiramente, o espaço internacional é ocupado por agentes capazes de homologar recursos provenientes de campos nacionais, como capital econômico, escolar, científico ou político (DEZALAY; MADSEN, 2013). Enfim, é um espaço disputado por elites, inclusive elites de campos científicos periféricos. São elas quem competem por espaços e tomam posições no cenário internacional. Em segundo lugar, o horizonte possível das representações através das quais se dão as oposições entre os agentes 
em luta já fora estabelecido pelo polo dominante ("ortodoxo"), de forma que o polo dominado ("heterodoxo") encontra uma configuração discursiva limitada - mas possibilitadora - pela qual deve disputar o sentido: a "verdadeira globalização", uma "efetiva internacionalização", "epistemologias do Sul", "Teorias do Sul”. Afinal, os proponentes de uma concepção crítica quanto à internacionalização e à produção do conhecimento "ocidental" encontram interlocutores previamente estabelecidos que já estruturaram "as regras do jogo": ou se deve aceitá-las e disputá-las, ou o jogo deve ser abandonado.

\section{CONCLUSÃO}

Uma análise sociológica que enfatiza a relação entre os campos sociológicos nacionais e as dinâmicas do espaço internacional deve considerar as dimensões em que se dá a inserção das práticas e das tomadas de posição dos agentes nacionais em distintos circuitos de circulação do conhecimento, sejam eles regionais ou internacionais, considerando a distinção de segmentos feita por Beigel (2013). Possíveis frentes de pesquisa empírica devem levar em conta, portanto, as diferentes publicações (em periódicos especializados, livros e capítulos de livros), as distintas mobilidades (formação doutoral, pós-doutoramento, como professores e pesquisadores visitantes), mas também práticas do cotidiano acadêmico, que expressam, além do mais, distintas tomadas de posições, ou estratégias, a depender das escolhas possíveis dos agentes.

O caráter da dependência acadêmica emerge quando consideramos a interlocução entre dinâmicas internas e externas dos campos nacionais, considerando que as disputas em torno da hegemonia no plano internacional também ressoam em práticas e posicionamentos de agentes nesse plano, conforme verificadas em ações de órgãos de financiamento de pesquisa, sistemas de avaliação da produção científica, políticas de internacionalização e consagração de pesquisadores por parte de instituições competentes.

\section{REFERÊNCIAS BIBLIOGRÁFICAS}

Alatas, Syed Farid.The study of the social sciences in developing countries: Towards an adequate conceptualization of relevance. Current Sociology, v. 49, n. 2, p. 1- 19, 2001. Academic dependency and the global division of labour in the social sciences. Current Sociology, v. 51, n. 6, p. 599 - 613, 2003.

. A definição e os tipos de discursos alternativos. Estudos Históricos, v. 23, n. 46 , p. $225-245,2010 "$ 
La dependencia académica: el desafio intelectual. In: BeIgel, F.; SABEA, H. (orgs) Dependencia académica y profesionalización en el Sur. Perspectivas desde la periferia. Mendonza: Ediunc e Sephis, 2014, p. 33 - 4.

Alatas, Syed Hussein. Intellectual imperialism: Definition, traits, and problems. Southeast Asian Journal of Social Science, v. 28, n. 1, p. 23 - 45, 2000.

BASALla, George. The spread of Western science. Science, v. 156, n. 3775, p. 611 - 622, 1967. Beigel, FERNANDA. (org) Autonomía y dependencia académica. Universidad e investigación científica emum circuito periférico: Chile y Argentina (1950 - 1980). Buenos Aires: Biblos, 2010.

Centros y periferias em la circulação internacional del conocimiento. Nueva Sociedad, n. 245, p. 110 - 123, 2013.

Publishing from the periphery: Structural heterogeneity and segmented circuits. The evaluation of scientific publications for tenure in Argentina's CONICET. CurrentSociology, v. 62, n. 5, p. $743-765,2014$.

El nuevo carácter de la dependencia intelectual. Cuestiones de sociología, n. 14, p. 1 - 17, 2016.

BHAMBRA, Gurminder. As possibilidades quanto a uma sociologia global: uma perspectiva pós-colonial. Sociedade \& Estado, v. 29, n 1, p. 131 - 151, 2014.

Boncourt, Thibaud. What 'internationalization' means in the social sciences? A comparison between international political science and sociology associations. In: Heilbron, Johan; Sora, Gustavo, Boncourt, Thibaud (org.) The social and human sciences in global power relations. Cham: Palgrave Macmillan, 2018, p. 95 - 123.

Bourdieu, Pierre. O Campo científico. In: Ortiz, R. (org.) Bourdieu. Sociologia. 2 ed. São Paulo: Editora Ática, 1983, p. 122 - 155.

. The social conditions of the international circulation of ideas. In: SHUSTERMAn, R. (org.) Bourdieu: A critical reader. Londres: Blackwell, 1999, p. 220 - 228.

. Os usos sociais da ciência. Por uma sociologia clínica do campo científico. São Paulo: Editora Unesp, 2003.

. Science of Science and Reflexivity. Chicago and Cambridge: The University of Chicago Press and Polity, 2004.

. A economia das trocas linguísticas. São Paulo: Edusp, 2008.

Braga Filho, Edmar Machado. Dimensões internacionais da prática científica e a formação de um campo sociológico nacional. Dissertação (Mestrado em Sociologia). Rio de Janeiro. Instituto de Filosofia e Ciências Sociais, Universidade Federal do Rio de Janeiro, 2019.

Buchнolz, Larissa. What is a global field? Theorizing fields beyond the nation-state. The Sociological Review Monograph, v. 64, n. 2, p. 31 - 6o, 2016. 
Burawoy, Michael. Challenges for a global sociology. Contexts, v. 8, n. 4, p. 36 - 41, 2009. CARdoso, Fernando H.; Faletto, Enzo. Dependência e desenvolvimento na América Latina. 8 ed. Rio de Janeiro: Civilização Brasileira, 2004.

Connell, Raewyn. Southern theory. The global dynamics of knowledge in social science. Sydney: Allen \&Unwi, 2007.

. A iminente revolução na teoria social. Revista Brasileira de Ciências Sociais, v. 27, n. 80, p. 9 - 20, 2012.

Costa, Sergio. Desprovincializando a sociologia: a contribuição pós-colonial. Revista Brasileira de Ciências Sociais, v. 21, n. 6o, p. 117 - 134, 2006.

Dezalay, Yves; Madsen, Mikael. Espaços de poderes nacionais, espaços de poderes internacionais: estratégias cosmopolitas e reprodução de hierarquia sociais. In CANÊDO, Leticia. et al. (org.) Estratégias educativas das elites brasileiras na era da globalização. São Paulo: HUCITEC Editora, 2013, p. 23 - 52.

Dubrow, Joshua; Kolczynska, Marta; Slomczynski, Kazimierz; Tomescu-Dubrow, Irina. Sociologists everywhere: Country representation in conferences hosted by the International Sociological Association, 1990 - 2012. Current Sociology, v. 66, n. 3, p. $466-489,2015$.

Gareau, Frederick. Another type of Third World dependency: the social sciences. International Sociology, v. 3, n. 2, p. 171 - 178, 1988.

Go, Julian; KRAUSE, Monika. Fielding transnationalism: An introduction. The Sociological Review Monograph, v. 64, n. 2, p. 6 - 30, 2016.

GIDDENs, Anthony. Novas regras do método sociológico: uma crítica positiva às sociologias interpretativas. Lisboa: Grandiva, 1996.

Hanafi, Sari. University systems in the Arab East: Publish globally and perish locally vs publish locally and perish globally. Current Sociology, v. 59, n. 3, p. 291 - 309, 2011. HeIlbron, Johan. Social sciences as an emerging global field. Current Sociology, v. 62, n. 5, p. $685-703,2013$.

HeIlbron, Johan.; Boncourt, Thibaud; SorÁ, Gustavo. Introduction. In: (org.). The social and human sciences in global power relations. Cham: Palgrave Macmillan, 2018, p. 1 - 25. HEY, Ana. Esboço de uma sociologia do campo acadêmico. A Educação Superior no Brasil. São Carlos: EdUFSCAR, 2008.

IANNI, Octavio. Globalização: Novo paradigma das ciências sociais. Estudos Avançados, v. 8 , n. 21, 1994, p. $147-163$.

KeIM, Wiebke. Social sciences internationally: The problem of marginalisation and its consequences for the discipline of sociology. African Sociological Review, v. 12, n. 2, 2008, p. $22-48$. 
Counter hegemonic currents and internationalization of sociology. Theoretical reflections and one empirical example. International Sociology, v. 26, n. 1, 2011, p. $123-145$.

. Conceptualizing circulation of knowledge in the social sciences. In:KeIM, W. et al. (org.) Global knowledge in the social sciences. Made in circulation. Londres: Ashgate, 2014, p. 87 - 113 .

Kenway, Jane.; FAHEY, Johannah. (org.) Globalizing research imagination. Abington: Routledge, 2009.

KnöBL, Wolfgang. Reconfigurações da teoria social após a hegemonia ocidental. Revista Brasileira de Ciências Sociais, v. 30, n. 87, p. 5 - 17, 2015.

KRAUSE, Monika. "Western Hegemony" in the social sciences; fields and model systems. The Sociological Review Monograph, v. 64, n. 2, p. 194 - 211, 2016.

Marginson, Simon. Global field and global imagining: Bourdieu and worldwide Higher Education. British Journal of Sociology of Education, v. 29, n. 3, p. 303 - 315, 2008. MarTín, Eloísa. Publicação acadêmica internacional e o lugar do Brasil na sociologia global. In: Pinheiro, Claudio et al. (org.) Ateliê do pensamento social. Práticas e textualidades. Rio de Janeiro: Editora FGV, 2015, p. 47 - 70.

. Current Sociology and the challenges of inequalities in academia: 65 years forging spaces of intelligibility. Current Sociology, v. 65, n. 3, p. 327 - 335, 2017.

. (Re) produção de desigualdades e (re) produção de conhecimento: a presença latino-americana na publicação acadêmica internacional em Ciências Sociais. In: MARTín, Eloísa.; GöBEL, Barbara (org.) Desigualdades interdependentes e geopolítica do conhecimento. Negociações, fluxos, assimetrias. Rio de Janeiro: 7 Letras, 2018, p. 56 - 80 .

Medina, Leandro. Centers and peripheries in knowledge production. Nova Iorque: Routledge, 2014.

Mosbah-Natanson, Sébastien; Gingras, Yves. The globalization of social sciences? Evidence from a quantitative analysis of 30 years of production, collaboration, and citations in the social sciences (1980 - 2009). Current Sociology, v. 62, n. 5, p. 626 - 646, 2013. ОмовошаLe, Ayokunle. La dependencia y las publicaciones académicas de los cientistas sociales de uma selección de universidades de Nigeria. In: Beigel, Fernanda.; SABEA, Hanan (org.) Dependencia académica y profesionalización em el Sur. Perspectivas desde la periferia. Mendonza: Ediunc e Sephis, 2014, p. 141 - 150.

Oommen, Tharailath.Asian presence in the International Sociological Association. Current Sociology, v. 64, n. 6, p. 833 - 852, 2016.

OrTIZ, Renato. Internationalization of the Social Sciences: a reflection. Sociologiesin Dialogue, v. 2, n. 1, p. 31 - 45, 2016. 
Pinheiro, Claudio. et al. (org.) Ateliê do pensamento social. Práticas e textualidades. Rio de Janeiro: Editora FGV, 2015.

PlatT, Jennifer. A brief history of the ISA: 1949 - 1997. Québec: International Sociological Association, 1998.

RAHBARI, Ladan. Peripheral position in social theory. Limitations of social research and dissertation writing in Iran. Civitas, v. 15, n. 1, p. 155 - 165, 2015.

Ribeiro, Gustavo.Outras globalizações. Cosmopolíticas pós-imperialistas. Rio de Janeiro: EdUerj, 2014

Steinmetz, George. Scientific autonomy, academic freedom, and social research in the United States. Critical Historical Studies, v. 5, n. 2, p. 281 - 309, 2018.

Organização das Nações Unidas para a Educação, a Ciência e a Cultura (UneSCO). World Social Science Report. Knowledge Divides. Paris: Unesco, 2010.

Vanderstraeten, Raf.; Eykens, Joshua. Communalism and internationalism. Publication norms and structures in international social sciences. Serendipities. Journal for the Sociology and History of the Social Sciences, v. 3, n. 1, p. 14 - 28, 2018.

VESSURI, Hebe et al.Excellence or quality? Impact of current competition regime on science and scientific publishing in Latin America and its implications for development. Current Sociology, v. 62, n. 5, p. 647 - 665, 2014.

Recebido: 25/03/2020 | Aprovado: 05/01/2021 